\title{
Campo cultural y la sociedad editora amauta. La otra aventura de José Carlos Mariátegui
}

Sección ESTUDIOS

RECIBIDO: 01/07/2021

APROBADO: 05/09/2021

PUBLICADO ONLINE: 30/11/2021

\author{
Osmar Gonzales Alvarado \\ Universidad Ricardo Palma \\ osmar.gonzales@gmail.com \\ https://orcid.org/0000-0003-4749-1460
}

\section{RESUMEN}

En las siguientes páginas, el autor describe y analiza el papel de la Sociedad Editora Amauta fundada en Lima, en 1926, por los hermanos José Carlos y Julio César Mariátegui, tanto para influir en el debate intelectual, artístico e ideológico como para impactar en el poco expandido mercado del objeto impreso, gracias a la impresión de la revista Amauta y de un conjunto de libros, de manera primordial. Para lograr sus propósitos, los hermanos empresarios tejerían una amplia red de agentes distribuida por gran parte del territorio nacional, así como un sistema de alianzas con algunos editores y autores del extranjero.

PALABRAS CLAVE: palabra impresa, autor, Editora Amauta, Imprenta Minerva, cultura

\section{Cultural field and the Amauta Publishing Society.} The other adventure of José Carlos Mariátegui

\section{ABSTRACT}

In the following pages, the author describes and analyzes the role of the Sociedad Editora Amauta founded in Lima in 1926 by brothers José Carlos and Julio César Mariátegui, both to influence the intellectual, artistic and ideological debate and to impact the littler expanded market of the printed object, thanks to the printing of the Amauta magazine and a set of books, mainly. To achieve their goals, the business brothers would weave a wide network of agents distributed throughout much of the national territory, as well as a system of alliances with some foreign publisher and authors. KEYWORDS: Printed word, author, Publisher Amauta, Minerva Printing, culture 
n uno de sus textos seminales sobre el campo cultural, Pierre Bourdieu (2002) - llama la atención sobre la doble significación del libro, tanto en la cultura como en el mercado'. El mercado, precisa, representa el nivel de autonomía que ha alcanzado el autor, pues ya no depende del mecenas ni de un círculo pequeño a quien debe someter su obra a la crítica, sino al público lector y consumidor simultáneamente, que es anónimo. Por su parte, Roger Chartier (1996) ha señalado que los autores no escriben libros, sino textos que luego adquieren una materialidad específica, y que es resultado tanto de un proceso tecnológico como de una sociabilidad particular que involucra a diversos agentes y procesos. Cada una de estas dos esferas obliga a diferentes políticas públicas (es distinta la función del libro en el estante de una biblioteca, a la que se presenta en el mostrador de una librería) aunque, no obstante, no están disociadas, sino que establecen conexiones entre sí que a veces están comandadas por el agente comercializador, y otras veces por el propio sujeto creador.

Lewis A. Coser (1966) nos muestra tomando casos como el de Charles Dickens, por ejemplo: cómo el propio autor se convierte en su promotor, es decir, a partir de su obra literaria adquiere relevancia, gracias a su propia agencia, como un autor de altas ventas de sus libros. En el Perú se puede mencionar el caso de Clorinda Mato de Turner, la autora indigenista de Aves sin nido, quien, para enfrentar una situación personal y económica difícil, estableció con sus hermanos la imprenta La Equitativa en la cual imprimía la publicación bisemanal Los Andes, y por cuyas páginas defendía al presidente Andrés A. Cáceres. Cuando el enemigo de este, Nicolás de Piérola, accedió al poder, sus fuerzas destruyeron la casa de la escritora, así como la imprenta, por lo que doña Clorinda debió huir del país y asilarse en Argentina. En este caso, se unieron tres aspectos: el del creador, el económico y el político.

De esta manera, el factor propio de la confección del objeto impreso se vuelve en un tema de por sí importante para el análisis. En este sentido, el filólogo Donald F. McKenzie (2005), ha despertado el interés por el estudio del "mundo de la edición", lo que llama sociología del texto o de la edición. Lo que señala es que el propio proceso de edición es fundamental no solo para entender la fabricación material del libro, sino porque también nos permite un acceso al propio contenido de la obra, a la cual ayuda a configurar. Si bien el tema de la distribución comercial del libro fue uno de los primigenios temas de interés para McKenzie, luego desarroIlaría a plenitud cómo la producción del libro es un vehículo de transformación del conocimiento y la información.

1 Agradezco a Isabel Cristina López Eguren por sus sugerencias y comentarios que me permitieron mejorar la primera versión de este texto. 
En las siguientes páginas, describo y analizo el papel de la Sociedad Editora Amauta fundada en Lima, en 1926, por los hermanos José Carlos y Julio César Mariátegui, tanto para influir en el debate intelectual, artístico e ideológico como para impactar en el poco expandido mercado del objeto impreso, gracias a la impresión de la revista Amauta y de un conjunto de libros, de manera primordial. En la base del proyecto estaba la legitimidad que José Carlos Mariátegui ya había alcanzado como autor. Para lograr sus propósitos, los hermanos empresarios tejerían una amplia red de agentes distribuida por gran parte del territorio nacional, así como un sistema de alianzas con algunos editores y autores del extranjero. De este modo, los Mariátegui impactaron simultáneamente en ambas esferas del libro: gracias a la circulación y comercialización del objeto impreso pudieron transmitir conocimiento e información y, con ello, ampliar el número de los lectores/consumidores. Asimismo, y de una manera no visible para el público, pusieron en práctica un novedoso sistema de ventas de acciones, de ventas adelantadas, de promoción y de canjes que renovaron el mundo editorial establecido hasta entonces en el Perú de las primeras décadas del siglo XX. Antes de entrar en este terreno, es preciso hacer un breve recorrido histórico.

\section{La Editorial, librería e imprenta Minerva}

En el mes de mayo de 1924, es decir, al año siguiente de su regreso al Perú luego de su estancia en Europa, José Carlos Mariátegui sufriría un decaimiento en su salud por lo que tuvieron que amputarle una pierna. Sus condiciones de vida variaron sustantivamente al quedar postrado en una silla de ruedas. Ello ocasionó que las posibilidades de trabajo se hicieran más difíciles, más aun cuando sus responsabilidades familiares habían incrementado, pues regresó con una esposa y un hijo. ${ }^{2}$ Es entonces cuando ante la apremiante necesidad de generar ingresos funda con su hermano Julio César la Editorial, librería e imprenta Minerva.

Los hermanos Mariátegui establecieron una empresa de publicación y venta de libros y revistas que sería la más importante de su tiempo. Mientras Julio César era el hombre de negocios, José Carlos era el estratega intelectual. Ya Julio César había incursionado en el rubro editorial periodístico cuando, gracias a su imprenta de pequeño calado, editó en Huacho, entre los años 1919 y 1922, los periódicos La Voz del Pueblo y La Voz del Valle, que él mismo dirigió y fundó (Anónimo). En 1925 decidió ampliar su negocio y adquirió una Máquina Tipográfica a la Sociedad

2 Antes de partir a Europa había nacido su primogénita, fruto de un compromiso anterior. 
Nebiolo-Torino — representada en el Perú por Reiser Curioni \& Cariozzi (Calle San José 313-Casilla 1619)—, que contaba con características importantes: entintado cilíndrico "Export 6", movimiento a motor, escuadra automática, portapliegos, recibidor resmador de las hojas de un lado, abanico. El precio fue de 49,368 liras. Al mismo tiempo, adquirió una máquina guillotina, bastante moderna para su época al precio de 11,000 liras (Turín, 12 de marzo de 1925). Los pagos lo realizaba puntualmente al Banco Italiano de Lima (Archivo José Carlos Mariátegui). ${ }^{3}$

Por su parte, José Carlos, más pragmático de lo que se puede suponer, concibió a la Editorial Minerva como empresa y no solo como una plataforma para difundir pensamiento y promover autores. Al final de cuentas, era una manera de proveerse de ingresos que le permitieran vivir sin la precariedad de depender de los pagos que recibía (no siempre puntualmente) por sus colaboraciones en diarios y revistas, peruana o extranjeras. Se debe recordar que Mariátegui no era un desconocedor de lo que significaba la producción editorial. Al contrario, fue participante estelar en el periodismo y no solo como articulista, sino también como gestor. Si en el periódico La Prensa aprendió todo lo necesario para la producción de un impreso, luego de su salida de ese diario Mariátegui incursionaría en la gestión de periódicos y revistas cuando quiso comprar El Tiempo y dirigió La Noche, Nuestra Época, La Razón, entre otros emprendimientos. Como precisa Guido Podestá Airaldi (2018): “A lo largo de una década, Mariátegui inventó un sinnúmero de revistas y periódicos así supiera de antemano, en un caso al menos, que alguna estaba destinada más que condenada a circular una sola noche, puesto que las circunstancias así lo ameritaban" (70-71). Ese caso efímero fue La Noche (además que se trata del "diario perdido" de Mariátegui), fundado exclusivamente para "exasperary provocar"al presidente José Pardo y Barreda. Abreviando, José Carlos no solo era un hombre de ideas, aunque ello no resta que el cerebro empresarial de la editorial era Julio César.

Además, y como no podía ser de otra manera, Mariátegui acometió su aventura editorial proveyéndola de reflexión y de un sentido crítico. Por ello, publicó tres artículos sobre el libro y la industria editorial —es decir, sobre el libro como objeto cultural y sobre el libro como mercancía-, que reflejaban una visión muy moderna. Entre 1927 y 1928 plasmó sus ideas y preocupaciones en "El índice libro" y "El problema editorial" (1927), y "La batalla del libro" (1928). Resumiendo su argumento, se puede decir que Mariátegui llama la atención sobre la poca cantidad de lectores que hay en el Perú, en la debilidad de la industria editorial y en la desprotección de

3 En adelante: Archivo. El Archivo José Carlos Mariátegui (archivo.mariategui.org) contiene información valiosa de primera mano que he consultado profusamente para este artículo. 
los autores, situación ante la cual reclama por lo que hoy llamaríamos una política pública dirigida a fomentar el libro y la industria editorial.

Es importante saber que sería José Carlos quien convencería a su hermano de instalar la empresa en Lima. Así, el 31 de octubre de 1925 sería inaugurada la Editorial, librería e imprenta Minerva, ${ }^{4}$ ubicada en la calle Sagástegui 669, hoy Av. Abancay, cerca al Parque Universitario. ${ }^{5}$ Mariátegui era consciente de la necesidad de publicidad para hacer conocidas las obras que editaba. Por ello le pide a su amigo, el periodista Ricardo Vegas García, de gran ascendencia entre sus colegas, que interceda para lograr la publicación de un aviso (cuyo contenido Mariátegui anexa en la carta) en la importante revista Variedades (Lima, 23 de noviembre de 1925) (Mariátegui 103). El pedido tuvo rápido eco. En efecto, el primer aviso publicitario de la editorial Minerva aparecería en dicha revista el 28 noviembre de 1925, anunciando la aparición del primer libro de Mariátegui: La escena contemporánea, dentro de la colección Biblioteca Moderna, al precio de un sol y 80 centavos, y disponible en "las mejores librerías". Es posible suponer que ante las urgencias económicas ante las que se enfrentaba, y que requerían una solución inmediata, Mariátegui reunió en un solo volumen las reflexiones escritas que habían aparecido principalmente en las revistas Variedades y Mundial.

Paralelamente, José Carlos enviaría ejemplares de su libro a personalidades de las letras de diversos países con el fin de hacerse conocido, promover reseñas a su libro, difundir su proyecto editorial, conseguir suscriptores y atraer compradores. Como se puede corroborar gracias a la correspondencia de Mariátegui, la aparición de La escena contemporánea tuvo muy buena acogida. En carta que remite a Samuel Glusberg, desde Lima el $1^{\circ}$ de enero de 1928, le dice que hasta ese momento ya se habían vendido 1500 ejemplares de ese, su primer libro (Mariátegui Tomo II 331). Los pedidos aumentaban en diferentes partes del país y así empezó la constitución de una red de agentes que estarían encargados de difundir y comercializar La escena contemporánea. Pero la idea de los Mariátegui de editar más libros ya estaba en sus mentes. El éxito de su primera publicación los animó a continuar con entusiasmo.

En carta a Carlos V. Chávez Sánchez, Mariátegui le escribe preguntándole si puede ser su agente en Piura, además de presentarle el proyecto editorial que tiene entre manos: "Ya estará Ud. enterado de lo que se propone la Editorial Minerva fundada por mi hermano: la edición de un libro mensual nacional o extranjero. Entre

4 El dibujo característico de la editorial fue creación del artista plástico Emilio Goyburu, también diseñador del primer libro-objeto del Perú: 5 metros de poemas de Carlos Oquendo y Amat, publicado por Mariátegui.

5 La inauguración de Minerva estuvo signada por la tragedia, pues al salir de la misma, el joven Edwin Elmore sería víctima de un disparo a manos del poeta José Santos Chocano y moriría pocos días después. 
los primeros irán El Nuevo Absoluto de Iberico Rodríguez, Tempestad en la Sierra (sic) de Luis E. Valcárcel, La aldea encantada de Abraham Valdelomar, una selección de cuentos de Manuel Beingolea, un libro de Antenor Orrego, Corazón payaso de [Luis] Guillén, una novela de Falcón y traducciones especiales para Minerva de libros de Istrati, Romain Rolland, Gorki y otros..." (Mariátegui 107).

En febrero de 1926, la Editorial Minerva empezaría a difundir el Boletín de libros y revistas en el que se daba a conocer títulos nacionales y extranjeros, también se divulgaban, por ejemplo, traducciones de autores italianos realizadas por el diplomático peruano y amigo del propio Mariátegui: Palmiro Macchiavello. Con estas acciones, los hermanos Mariátegui se procuraban ingresos que sirvieran para la edición de Amauta y, posteriormente de sus otros títulos. En setiembre, Mariátegui comenzaría a publicar su emblemática revista; también tendría éxito en cuanto a las valoraciones con respecto a su aporte cultural, como en relación con las ventas realizadas. Tan importante fue la acogida de la crítica y de los compradores que Mariátegui observó que era necesario ampliar el negocio, pues era real la posibilidad de lograr una proyección de sus ideas al mismo tiempo que generar ingresos importantes, como en efecto ocurrió. El número de lectores y consumidores podía ser incrementado simultáneamente. En conjunto, como sostiene Ricardo Melgar Bao (2009), Mariátegui daría sentido a la formación de un campo intelectual peruano.

\section{José Carlos Mariátegui: autor y editor}

José Carlos Mariátegui, como ha ocurrido en otros casos (Rivera Mir; Bello), representa ese tipo de figura intelectual que incursiona en el terreno de la materialización del objeto impreso. Está en esa delgada línea que une al autor con el editor en una sola persona. El caso de nuestro autor es, además, especialmente atractivo y sugerente, modélico para entender otros procesos intelectuales individuales. Recordemos que Mariátegui no había concluido siquiera los estudios primarios y que se desarrollaría como autodidacta cimentando una profunda vocación por la lectura y la escritura. En su enfermedad, y la soledad que conllevó, los libros fueron su principal alivio y compañía espiritual. Al hecho de tener una salud deteriorada se sumaba su situación económica que jugaba en contra de su vocación como hombre de letras. Por ello trabajó desde muy joven, y lo hizo en el mejor lugar para sus inclinaciones intelectuales y artísticas: el periódico, específicamente La Prensa, que no solo era uno de los más prestigiosos del Perú, sino que además había incorporado a buena parte de la vanguardia de los escritores de su tiempo (Abraham Valdelomar, Leonidas Yerovi, Federico More, Alberto Ulloa, entre otros) y ostentaba una visión de la política muy 
distante de la civilista predominante. Se trataba, pues, de una publicación ubicada en la vanguardia de los intelectuales-periodistas, que marcó época y que significó una renovación trascendental en el periodismo nacional.

Mariátegui ingresó a La Prensa en 1909 a la edad de 15 años para cumplir funciones muy modestas, como operario, alcanzarrejones, y desde ahí, gracias a su inteligencia vivaz y persistencia, iría escalando en la organización periodística cumpliendo otras tareas cada vez de mayor responsabilidad y envergadura, hasta ser parte de las oficinas de redacción, escribiendo noticias breves, policiales o de lotería; también incursionaría en sociales, hípica, pergeñaría algunas rimas y una obra de teatro, hasta llegar a ser uno de los principales periodistas de su época. A partir de su experiencia fundamental en La Prensa (que extendería a otros diarios como El Tiempo, La Noche, La Razón), Mariátegui se revelaría como hombre de letras, y después de su regreso de Europa en 1923, como ideólogo y político. Es decir, el autodidacta Mariátegui se iría constituyendo en un proceso en realidad breve, en un autor legitimado y reconocido en tanto hombre de letras y de pensamiento. En ese lapso iría desentrañando tanto los secretos de la buena escritura como los de la producción material de los textos. El José Carlos Mariátegui que en 1925 fundara con su hermano la Editorial, imprenta y librería Minerva, ya era un hombre cuajado en esas lides. Estaba preparado para enfrentar tal empresa. Su último hijo, Javier, resume muy bien el trayecto del Amauta:

Mariátegui se forjó y realizó gracias al ejercicio temprano de las letras — como en los tiempos renacentistas que juntaban a escritores con impresores-, en los talleres de un gran diario. En esos talleres, José Carlos fue primero ayudante de "taller" ("alcanzarrejones"), pero pronto accedió a una posición especial: fue una especie de bus-boy, encargado de relacionar a los periodistas con los linotipistase impresores. De ese modo conoció y dominó la dinámica misma de la relación entre la palabra escrita y su concreción tipográfica...Fue la imprenta primero y después el diario, su primer y decisivo aprendizaje (Mariátegui Chiappe 22).

En sentido estricto, Mariátegui sería primero editor, y luego autor. Comprende a la perfección las exigencias del trabajo editorial, como se puede apreciar en unas líneas dirigidas al poeta José María Eguren. Con rubor, le confiesa que su libro, 7 ensayos de interpretación de la realidad peruana, ha salido primero que el de su amigo poeta, "como no debía", y explica la razón: "... pero la imprenta necesita el tipo. Lo material condiciona siempre nuestros itinerarios" (Lima, 21 de noviembre de 1928) (Mariátegui Tomo II 478). 
Mariátegui entendía muy bien el peso de las exigencias materiales y sabía tomar decisiones.

\section{Sociedad Editora Amauta}

En este proceso, en setiembre de 1926 aparecería la revista Amauta, con un corte indigenista y vanguardista. El diseño y sentido estético correspondió al pintor José Sabogal. Gracias al contenido que portaban sus páginas, el lector podía conocer los debates intelectuales, ideológicos y políticos más actuales, tanto del Perú como del extranjero, especialmente de Europa. Amauta fue pensada por Mariátegui como una revista que dialogara con el mundo desde la reivindicación de lo nacional. En este caso, lo estético-formal tenía vinculación estrecha con el contenido artísticointelectual. Forma y fondo hicieron de esta una revista que rebasaba fronteras y tramontaba estándares. Un buen ejemplo del éxito en cumplir este propósito se encuentra en la carta que Earle K. James (New York, 25 de octubre de 1928) le escribe a Mariátegui en su calidad de encargado de la columna sobre literatura hispanoamericana. En ella le confiesa que Amauta le ha encantado, y que le ha despertado el interés por una producción intelectual como la peruana, que no conocía: "Hasta ahora se han comentado principalmente libros argentinos, chilenos y mexicanos. Estoy deseoso de conocer más de lo que se está haciendo en el Perú, especialmente entre la generación nueva..." (Mariátegui Tomo II 464). Dos semanas después (Nueva York, 6 de noviembre de 1928), James complementaría su diagnóstico:".. . las casas editoriales argentinas son las únicas activas en distribuir sus libros" (467). También le comenta a Mariátegui que le han impresionado las pinturas de Sabogal, y que quiere reproducciones de las mismas. Contenido intelectual y mensaje estético son mutuamente complementarios en Amauta.

Por otra parte, Amauta también cumpliría otro papel, el de la comunicación interna, pues en sus páginas aparecería diversa publicidad sobre sus títulos que ya están en circulación o las que están en proceso de edición; informes dirigidos a sus accionistas; la realización de campañas como la quincena a favor de Amauta; actividades culturales organizadas por la propia revista, y otros anuncios que serían fundamentales en el propósito de difundir la revista así como las actividades de su empresa editorial. En este sentido, el número 8 de Amauta (abril de 1927) traería una noticia trascendental para lo que era la precaria constitución del campo cultural en el Perú. Era el anuncio de la fundación de la Sociedad Editora Amauta.

A página entera, "La Dirección” daba a conocer al público lector que la revista había logrado un "éxito extraordinario" que sus directores consideraban único en 
una publicación de su género. También señalaban orgullosamente que la revista había sido económicamente autosuficiente gracias a la venta de sus ejemplares. Sin embargo, acotaban, la creciente demanda que había generado sobrepasaba sus capacidades financieras, lo que les impedía seguir creciendo. Las razones eran varias, según enumeran: la demora de las remesas tanto de las agencias de provincias como las del extranjero; la urgencia de la administración de tener créditos que le permitieran crecer, y la necesidad de importar papel, tinta y materiales para obtener mejores resultados en la impresión.

Los directores entendían que para que la aventura editorial creciera debían pasar del esfuerzo individual a una gestión económica colectiva. Es así que convocan a todos los amigos y lectores a que contribuyan con la empresa, subrayando que con el éxito alcanzado se garantizaba la seguridad de la inversión. Como prueba fehaciente, señalan, ahí está la circulación que ya tiene Amauta en el Perú e Hispanoamérica, así como la red de agencias ya establecida en provincias.

Los directores hacen hincapié en que se trata de una revista exitosa sin déficit económico. La venta y suscripciones han sufragado los gastos necesarios; los anuncios publicitarios todavía son insuficientes, aunque ya han previsto una solución“... porque en AMAUTA la circulación debe preceder y motivar la publicidad". Evidentemente, se trata de una visión empresarial moderna la de los hermanos Mariátegui. Asimismo, los directores anuncian sus planes: mantener las colecciones de lujo para los Amigos de Amauta y las ediciones corrientes; además que se incluirá la publicación de libros bajo el sello Biblioteca Amauta, que estará a cargo de José Carlos.

El capital de la Sociedad es de Lp. 500.0.00 dividido en letras de cien acciones de Lp. 10.0.00 cada una. La mitad de la suma se pagará al momento de la suscripción de la acción, la otra mitad será pagada en cinco cuotas y en cinco meses. El directorio será designado por los accionistas y estará conformado por el director de Amauta, José Carlos Mariátegui, y el gerente de la Editorial Minerva, Julio César Mariátegui. La Sociedad Editora Amauta firmará contrato con Minerva para la impresión de Amauta y de sus ediciones, así se abaratarán costos, informan. La comunicación deberá ser dirigida a la dirección del propio José Carlos: Washington Izquierda No. 544, Casilla de Correo 2017, Lima. La primera reunión de accionistas se realizará el 15 de mayo de 1927.

Finalizan el anuncio los directores con una recordación: "A todos les recordamos que no basta que AMAUTA subsista. Es necesario que crezca y que dé todos sus frutos".

Según la situación financiera de la revista al 30 de abril de 1927, la venta de ejemplares es la principal fuente de ingresos S/ 2,843.81, seguida por las suscrip- 
ciones con $S / 957.75$, y por los anuncios con $S / 1,592.50$. Queda en caja, año 1926, S/ 200.00. En total: S/ 5,544.06. Los gastos están distribuidos del siguiente modo: impresión y administración $S / 5,051.48$; gastos en correo $S / 254.00$, y gastos generados $S / 95.00$. Total: $5,400.48$. El saldo que queda a favor es de $S / 143.58$. Por otra parte, el valor del archivo es de $S / 577.78$, la suma de los deudores es de $S / 1,743.68$, y de los acreedores es de $S / 866.08$.

En el número 9 de Amauta (mayo de 1927) los directores de la Sociedad se complacen del éxito de su convocatoria. Afirman que la Sociedad Editora Amauta no es un proyecto, sino una realidad. Hasta ese momento ya se habían vendido 51 acciones, y esperan que la cifra se incremente con las solicitudes que deben llegar desde las provincias. La primera reunión de accionistas se llevó a cabo el 15 de mayo, en ella se establecieron las bases del Estatuto, las que, entre otros aspectos, señalan que se trata de una sociedad anónima. Su directorio constará de cinco miembros, entre los cuales figuran el director de la revista Amauta, José Carlos, y el gerente de la Editorial Minerva, Julio César Mariátegui.

\section{La inscripción notarial de la sociedad}

La inscripción notarial de la Sociedad Editora Amauta se efectuó en la Notaría del Dr. Godofredo Loli, ubicada en la Calle Negreiros 521, teléfono 1731, en Lima, el 21 de mayo de 1928. En el "Testimonio de la Sociedad Editora Amauta", número 801, se consigna el apersonamiento del director José Carlos Mariátegui y del gerente, Ricardo Martínez de la Torre, con domicilio en Av. Industrial 232, como representantes de la sociedad. Portaban una minuta firmada de sociedad anónima para que sea inscrita en los Registros de Escrituras Públicas, que es archivada en el legajo 170; se incluyen los estatutos con fecha Lima, 10 de mayo de 1928. El día 23 de mayo pagaron la suma de Lp. 8.75. Se registró el acta de la primera junta general de accionistas, que a la fecha ya constaba de 82 (Archivo).

La segunda acta registra la composición del directorio: Emilio Romero, Ricardo Martínez de la Torre, Carmen Saco, Avelino Navarro, Antonio Tincopa Pineda, José Carlos Mariátegui. Firman: Miguel Adler, Antonio Tincopa Pineda, Pedro Augusto Posada, B. Bighman, Fabio Camacho y Martínez de la Torre. En esta acta consta que José Carlos propuso el establecimiento de un quiosco"originalmente decorado" para la venta de libros y revistas, así como una pequeña instalación en Radio Telefónica para conferencias y otras actividades. Para ello era necesario aumentar el capital de la sociedad de 500 a 700 libras ampliando 50 acciones a las 100 anteriores. Firman el acta: Carmen Saco, Emilio Romero, José Carlos Mariátegui, Miguel Adler, Avelino 
Navarro, Ricardo Martínez de la Torre, Antonio Tincopa Pineda, Teodoro Elmore y Óscar Herrera. La sociedad sería inscrita el 7 de setiembre de 1928. La notaría expediría el primer testimonio el 15 de setiembre de 1928.

La empresa se inició con el capital efectivo de tres mil libras peruanas con la siguiente proporción: 2,250 de Julio César y 750 de José Carlos. El objeto de la sociedad era la explotación de los negocios de imprenta y de edición y comercio de libros y giraría bajo la razón social: "J.C. Mariátegui y Cía.-Imprenta y Editorial Minerva”.

Mientras José Carlos asumía la dirección artística, intelectual y literaria, Julio César lo haría con la gerencia administrativa, editorial e industrial. Ambos hermanossocios tendrían las funciones de director y gerente, respectivamente. La duración de la sociedad sería de diez años contados desde el primero de enero de 1926. Además, Julio César administraría la librería y percibiría un sueldo de diez libras peruanas. Una parte de las utilidades, no menor del 30\%, sería destinada a un fondo de reserva.

La sociedad de los hermanos Mariátegui tendría una influencia central en la divulgación de las nuevas ideas que fermentaban en el Perú en la segunda década del siglo XX. Entre 1925 y 1930 publicaron alrededor de 40 obras. Gran parte de estas pertenecieron a autores que se convertirían en clásicos del pensamiento social peruano; incluso nombres que hoy reconocemos como fundamentales tienen su bautizo público gracias a esta sociedad.

\section{Personajes de una sociabilidad letrada}

Es necesario detenerse un momento en algunos nombres dada su ubicación en el proceso social, intelectual, artístico y político peruano. Carmen Saco, que ocuparía la gerencia administrativa de la Sociedad, fue una artista plástica y escritora de preocupación social y defensora de los derechos de la mujer. Fue la primera peruana que visitaría la Unión Soviética. A mediados de los años 20, y gracias a una beca del gobierno peruano, realizó estudios en diversos países europeos. En Amauta colaboró con artículos sobre su experiencia soviética y otros motivos. Sus convicciones políticas la llevaron a ser una de las mujeres militantes del comunismo peruano. Por su parte, Emilio Romero, era un polifacético intelectual puneño, discípulo del gran pedagogo José Antonio Encinas. Destacaría por sus trabajos sobre geografía e historia económica peruanas, y por sus propuestas de descentralización. También incursionaría en la docencia universitaria, en la literatura y, sobre todo, en la política ejerciendo como congresista, ministro de Estado y embajador en diversas oportunidades. 
Un caso especial es el del judío rumano Miguel Adler, quien luego de la Gran Guerra huyó de su país, llegando al Perú. Fue uno de los mejores amigos de Mariátegui, y estuvo entre quienes lo acompañaron hasta sus últimos momentos de vida en la Clínica Villarán. Adler fundaría junto a su esposa Nomi Milstein la revista Repertorio Hebreo (1929), que sería patrocinada por Mariátegui e impresa en sus propios talleres. La pareja Adler-Milstein ayudaba a Mariátegui con traducciones del ruso y alemán. La dictadura de Luis M. Sánchez Cerro los expulsaría a ambos del país en el año 1931. En adelante, su vida la proseguirían como exiliados en diferentes países (Lomnitz; Gonzales).

Óscar Herrera, médico de profesión, tenía fama de sabio. Tendría un importante papel en su tiempo, pues en un inicio participó como líder juvenil de la APRA, antes de la ruptura de Mariátegui y Haya de la Torre, en 1928. Sería uno de los profesores de la Universidad Popular González Prada, y luego integraría la célula aprista de Buenos Aires. Después del intenso intercambio polémico entre mariateguistas y hayistas, se decantaría por los segundos.

Ricardo Martínez de la Torre vinculó actividad política, propaganda ideológica con la propia gestión de la Sociedad. Sería integrante del Grupo de Lima de Mariátegui que daría forma al Partido Socialista, actuando como secretario de propaganda. En la Sociedad Editora Amauta se desempeñaría como gerente, y escribiría uno de los primeros trabajos sobre el movimiento obrero publicado por la editorial de los Mariátegui: El movimiento obrero en 1919. Apuntes para una interpretación marxista de historia social del Perú (en cuya carátula se utilizaría el dibujo de George Grosz, "Blood is the Best Sauce”), de 1928. Una vez muerto Mariátegui, sería miembro del Partido Comunista del Perú y empleado de una agencia bancaria. Por otro lado, Avelino Navarro, también sería uno de los seguidores de Mariátegui. Javier Mariátegui Chiappe señala que Navarro llegó a Lima procedente de Jauja en 1927 para seguir estudios de derecho en la Universidad de San Marcos; ante la carencia de dinero, Mariátegui lo contrató como secretario a medio tiempo en 1929, y sería un asistente frecuente a las tertulias en la casa de Washington Izquierda. Como Martínez de la Torre, también integraría el Grupo de Lima y, siguiendo su ruta, tras la muerte del Amauta se incorporaría al Partido Comunista (Mariátegui Chiappe 154-156).

Lo que deseo dejar establecido es lo difícil que es establecer una línea divisoria excluyente entre la gestión editorial y el trabajo intelectual (sin mencionar la participación política). No existe una separación neta entre ambas actividades $y$, por el contrario, no es extraño que se traslapen. El mejor ejemplo es el propio Mariátegui. Diversos testimonios dan cuenta de cómo se involucraba en la propia edición de los textos que imprimía su Sociedad: definía la ubicación y tamaño de 
las fotos, los tipos de letras, los dibujos a utilizar, establecía relación directa con los autores que le interesaba publicar, entre otros aspectos. Con Eguren, por ejemplo, la correspondencia es específica, dentro de una comunicación que emana amistad y respeto mutuo. Eguren le escribe a Mariátegui (Lima, 29 de octubre de 1928):"Le mando las pruebas corregidas y una lista para la numeración de las composiciones. Sería bueno que suprimiera algunas. Todas las que juzgue necesarias" (Mariátegui Tomo II 465). Mariátegui, abrumado por la responsabilidad que le transfiere el poeta le responde (Lima, 21 de noviembre de 1928): "Me aterra la idea de una exclusión indebida. Quiero que el libro recoja todo aquello que Ud. estime y elija en su obra. No me perdonaría una omisión que pudiese desagradarle... Es excesiva mi responsabilidad" (478). El libro al que se refieren ambos es nada menos que La canción de las figuras, cuya primera edición había sido publicada en 1916, conjunto de poemas que se convertiría en emblemático de la poesía moderna peruana.

Igual ocurre con Enrique López Albújar, aunque el proyecto no llegaría a buen puerto. El escritor piurano era bastante detallista en el tipo de publicación que quería para su nueva obra, la novela que llamaría Matalaché. Inquiere con precisión a Mariátegui:"Quiero editar en la Editorial Minerva, siempre que sus condiciones me convengan, aquel libro, y para eso necesito un presupuesto. Cuánto me cobraría la casa por dos mil ejemplares en papel como el de La Escena Contemporánea, con el mismo formato de página, forro de papel satinado para recibir en la portada un dibujo en tres colores, pero mayor margen en blanco que el de su libro, pues querría que tuviera el tamaño de Cuentos Andinos, $2^{\text {a }}$. edición" (Piura, 6 de febrero de 1928) (348). Al parecer, cuando Mariátegui le envía el presupuesto solicitado a López Albújar este había empezado la impresión de su libro con el escaso dinero con el que el Municipio de Piura había decidido apoyarlo: 70 libras (Piura, 8 de abril de 1928) (365). Así son los negocios, a veces resultan, otras no. Mariátegui lo sabía muy bien.

Con Luis E. Valcárcel ocurre una situación singular. Desde el Cusco le envía los originales de lo que sería Tempestad en los Andes (Cusco, 7 de julio de 1926) y le pide a Mariátegui que redacte el prólogo (Mariátegui 165). Posteriormente, le comunica que Luis Alberto Sánchez escribirá "unas apostillas finales..." (Cusco, 28 de octubre de 1926) (186). Pero luego Sánchez inicia la llamada "polémica del indigenismo" que contravenía el espíritu del libro de Valcárcel y del propio Mariátegui, por lo que el escritor cusqueño se lamenta por "la intervención un poco inamistosa" de Sánchez, que ha "iniciado polémica tan inoportuna" (251). Como sabemos, Mariátegui decidió mantener tanto su prólogo como el epílogo de Sánchez, por 
más antagónico que haya sido a sus planteamientos. Esta fue una decisión como editor y autor, simultáneamente.

Desde otro ángulo de la edición comprobamos la atención que ponía Mariátegui en todos los aspectos. Manuel Beltroy fue un poeta y periodista con un fino manejo del idioma; también fue parte de la revista Mercurio Peruano que fundó Víctor Andrés Belaunde en 1918, y fue secretario privado de José de la Riva Agüero. Pero algo más: también era editor. En 1920 fundó Editorial Euforión, en donde publicó obras de importantes escritores como Abraham Valdelomar, Luis Alberto Sánchez, José Gálvez, y otros. Incluso tradujo la importante obra de Clements R. Markham, Los Incas del Perú. Precisamente, este es el aspecto que trata con Mariátegui, la traducción a la que se había comprometido de Bubu de Montparnasse, de Charles-Louis Philippe. Beltroy se encontraba en Montevideo trabajando para la Asociación Cristiana de Jóvenes, y ahí se enteró, al leer el Boletín de libros y revistas, que Mariátegui anunciaba la publicación del título mencionado. Apurado, Beltroy le escribe a su amigo editor: "Así es que reanudé mi trabajo, revisé la versión y la corregí, hice un proyecto de portada, falsa portada y primeras páginas para el libro en que habría de publicarse...y le envío todo eso ahora mismo en paquete postal certificado, juntamente con esta". Luego continúa con una serie de especificaciones sobre la corrección de pruebas, la distribución tipográfica, diseño de portada y otros. Aunque también le pregunta a Mariátegui cuál va a ser su participación en la publicación de dicho libro (Montevideo, 24 de abril de 1926, con Membrete de la Federación Sudamericana de Jóvenes de Asociaciones Cristianas de Jóvenes) (148). ${ }^{6}$

Acerca de la comercialización del libro, el propio Mariátegui revela su interés en carta que dirige a su amigo, el autor argentino, Samuel Glusberg, director de la editorial Babel (Lima, 10 de enero de 1928). Además de remitirle el reciente número de Amauta más dos ejemplares de Tempestad en los Andes, y de anunciarle el libro de poemas de Eguren así como de su propio libro 7 ensayos, Mariátegui le hace la siguiente consulta: "Tengo otro libro de tema internacional, como La Escena Contemporánea, al cual titulo Polémica Revolucionaria. No lo podría dar enseguida por Minerva, porque se diría entonces que no edito casi sino mis libros. Deseo saber, por esto, si podría editarlo Babel. Yo tomaría a firme 300 ejemplares para la venta en Lima, y al menos otros tanto podrían enviarse en

6 A propósito del aspecto de la traducción, también se debe mencionar al diplomático peruano y amigo de Mariátegui desde los tiempos de su estadía en Italia, Palmiro Macchiavelo Gonzales, que traducía textos del italiano para el Boletín de Libros y Revistas. Asimismo, el del escritor ancashino, Eugenio J. Garro, y de los mencionados Adler y Milstein.

7 Se trata del libro que se publicaría bajo el nombre de Defensa del marxismo. 
consignación, bajo mi responsabilidad, a los agentes de provincias que yo indicase" (Mariátegui Tomo II 330).

Constatamos a un Mariátegui atento a todos los aspectos de la producción y circuito del libro.

\section{La comercialización del libro}

Para solventar financieramente su empresa, los hermanos Mariátegui tomaron diversas decisiones y optaron por estrategias distintas y combinadas. Una de ellas fue convocar desde el inicio la suscripción de sus lectores, primero a la propia revista Amauta y después al libro mensual que la Sociedad Editora Amauta tenía proyectado cumplir. La profusión de cartas enviadas por José Carlos nos muestra la casi febril actividad que llevó a cabo con el fin de captar el mayor número de suscriptores, tanto en Lima, como en provincias así como en el extranjero.

En el Archivo José Carlos Mariátegui se puede encontrar un listado (que no está fechado) de suscriptores que revela el riguroso control que los hermanos empresarios llevaban al respecto, y que contiene información valiosa. De entre los 109 suscriptores de Lima podemos mencionar, por ejemplo, al poeta José María Eguren (Colmena, 462), la educadora Esther Festini de Ramos Ocampo (Magdalena del Mar), el estudiante y trabajador de la propia sociedad Avelino Navarro (Barranco), el líder sindical que integraría el Grupo de Lima Julio Portocarrero (Vitarte), el doctor y después emisario del propio Mariátegui en cónclaves internacionales Luis Pesce (Negreiros, 594), el trabajador y futuro dirigente aprista Arturo Sabroso (Fábrica Tejidos Santa Catalina), el periodista y diplomático Alberto Ulloa (Santa María, 534), y el gran amigo de Abraham Valdelomar, Atilio R. Minutto. Un apunte importante es que un significativo número de suscriptores eran trabajadores: 35 . De provincias se consigna a 58 suscriptores, tanto individuales (en gran parte los que actuaban como agentes) como institucionales, como las Bibliotecas Públicas de Arequipa y de Puno.

Otra estrategia fue la de vender acciones, iniciativa audaz en la que también tuvieron los hermanos Mariátegui importantes resultados. Mencionemos algunos nombres de los accionistas: Ricardo Martínez de la Torre era poseedor de la acción número 3; Julio Codesido de la 4; Raúl Porras Barrenechea de la 6; Teodoro Elmore era dueño de 5 acciones, de la 26 a la 30; la Sociedad Obrera Claridad adquirió 8 acciones, de la 55 a la 62; Carmen Saco era propietaria de la 69; Mario Bazán de la 70; Nicanor de la Fuente de la 71. Los amigos judíos de Mariátegui también fueron 
accionistas. Miguel Adler compró la acción número 5, el 11 de mayo de $1928^{8}$. El 25 de setiembre de 1928 lo hicieron José Lerner (51); Jacobo Rosenblit (52); Isaac Rabinovich (53), y Bernardo Regman (54) (Archivo).

Por otra parte, el sistema de agencias sería fundamental para que las publicaciones de la Sociedad circularan comercialmente y se adquirieran. Los hermanos Mariátegui pudieron comprometer a buen número de agentes en todo el país tejiendo una vasta red que involucraba a libreros, editores, y especialmente a autores que cumplían simultáneamente esas funciones. El prestigio intelectual de Mariátegui era lo que sostenía la capacidad de la Sociedad de involucrar a los agentes. Eso no impedía que se hiciera un seguimiento estricto de la distribución de ejemplares, de los pagos, de las deudas, todo dentro de un juego de porcentajes distribuidos de la siguiente manera: $25 \%$ por la venta de cada ejemplar; $20 \%$ por las suscripciones, cuya entrega sería responsabilidad del agente, y 15\% encargándose la propia Sociedad de la entrega. El agente se comprometía a distribuir los libros en su provincia, luego a cobrar las ventas y enviar el dinero a la Sociedad. En muchos casos, los agentes también eran importantes para establecer relaciones con intelectuales y conseguir que las publicaciones de sus espacios regionales colocaran avisos de los títulos de la Sociedad Editora Amauta o, en el mejor de los casos, comentarios sobre sus títulos.

La mención de algunos nombres de los agentes y de la localidad en la que actuaban nos puede permitir obtener un rápido panorama de la distribución en el país. Vale decir que cada uno tenía un peso importante en su región por ser editor de algún periódico, escritor o, en general, por ser una persona de cierta influencia. Estos son algunos de los agentes: Nemesio Guevara, de Palpa; Teodosio Muñoz, de Huanta; Miguel Meza V., de Pomabamba; A.F. Hurtado de Mendoza, de Morococha; Isaac Batallanos H., de Abancay; Neptalí La Madrid, de La Oroya; Manuel F. Laos, de Matucana; Román Landa Hinostroza, de Pampas; Carlos V. Chávez Sánchez, de Piura; M. Bracamonte y Dionizio Mendoza, de Chiclayo; Buillón Salazar y Máximo Pecho, de Jauja; Arturo Peralta (Gamaliel Churata), del Consejo Provincial de Puno; Lizardo Palacios, de Tarma; Manuel E. Lazarte y Angles H. Pinto, de Carhuaz; Lucas Oyague y Luis E. Valcárcel, de Cusco; César Atahualpa Rodríguez, de Arequipa. A esta lista hay que agregar a Sigüenza Céspedes, de la revista La Sierra; a la Secretaría General de la Federación de Chaufferes del Perú, y al señor Ruales de la Federación

8 Acerca de Adler, su nieto Claudio Lomnitz ha mencionado que cuando su abuelo debió salir expulsado del país por orden del gobierno de Sánchez Cerro, decidió que las acciones que había adquirido de la Editorial Amauta fueran donadas a Anna Chiappe, la viuda de Mariátegui (Lomnitz 138). Si bien Lomnitz habla de acciones, en plural, solo he encontrado la que he mencionado. 
de Yanaconas; La Acción, de Chincha; Librería Iberico, de Cajamarca; Librería Nieri, de Ica; Alcides Spelucín, de la Imprenta El Norte, Trujillo; Librería León Alvarado; Luis Carranza de Imprenta y Librería El Tiempo, de Piura, y Roberto la Torre, de la revista Kosko, de Cusco (Archivo).

Obviamente, era difícil que una red tan profusa funcionara sin contratiempos. Y se registran desaguisados de diferente naturaleza. Hay a quienes les deben corregir su trato descortés, como a Isaac Batallanos (Lima, 4 de agosto de 1928); en otras oportunidades, debido a las deudas sin pagar, el directorio de la Sociedad se ve obligado a cancelar la remisión de Amauta, como es comunicado a Nemesio Guevara (Lima, 25 de mayo de 1928), y en varios casos los directores deben recordar a sus agentes que su compromiso es cobrar el dinero de las ventas para enviarlo a Lima.

La comunicación con personalidades (peruanas o no) e instituciones del extranjero es profusa. Entre los peruanos que residen en el extranjero es posible mencionar a Jacobo Hurwitz y Esteban Pavletich, que estaban radicando en México; a Enrique Bustamante y Ballivian, establecido en Río de Janeiro; a Manuel Seoane y Fernán Cisneros, que se encontraban en Argentina. Todos ellos se muestran dispuestos a apoyar la labor de propaganda de los títulos de la Sociedad, de vincular a otros intelectuales y de buscar comentarios a los libros que vayan saliendo a la luz.

Con respecto a la lista de personajes de otros países vinculados al proyecto de los hermanos Mariátegui también es posible obtener un panorama. Así, de Argentina se puede mencionar a Samuel Glusberg, de editorial Babel, como también a Carlos Américo Amaya, de la revista Sagitario, de La Plata, quien además le da varias referencias de editoriales y librerías (La Plata, 25 de noviembre de 1925) (Mariátegui 105); de San José de Costa Rica a José García Monge, director de Repertorio Americano, a quien le plantea que sea agente de sus publicaciones y hacer canje (Lima, 24 de diciembre de 1925) (115), a lo que este accede rápidamente (27 de enero de 1926) (134). De Madrid a José María de Acosta; de La Habana a Enrique José Varona, y de La Paz a Mario Nerval. Librería Moderna de Sao Paulo, Brasil; L'Humanité, La Correspondence Internationale, La Revue Novelle de París; Vanitas de Santiago de Chile; El Consultor Bibliográfico de Barcelona; La Cruz del Sur, de Montevideo (Archivo).

Un papel importante cumplió la campaña llamada "la quincena Pro-Amauta". El 25 de enero de 1929, desde Lima, desde la Sociedad (no aparece firma en el documento) le escriben a Ricardo Martínez de la Torre y Mario Nerval, que se encontraban en La Paz, para explicar el sentido de dicha campaña: "Durante ella esperamos que todos nuestros amigos i simpatizantes nos ofrezcan su aporte económico sea renovando sus suscriciones, reclutándonos nuevos suscritores, los 
agentes abonando sus saldos, los lectores en general adquiriendo libros de los que editamos o de los que somos representantes. 0 , finalmente, poniendo en juego la iniciativa particular" (Archivo).

Por otra parte, los ingresos de la sociedad no solo se debía a la venta de libros y revistas Amauta, Boletín de libros y revistas y Labor, sino que también ofrecían artículos diversos como: tarjetas de felicitación por Año Nuevo con o sin sobres, en blanco o impresos y de variados tamaños y calidad; también agendas, además de la impresión de artículos de escritorio, papel de cartas, papel para máquinas de escribir, libros para colegio y cuadernos de escritura.

\section{Autores y títulos}

A los nombres de autores y títulos de libros que se han ido mencionando a lo largo de las páginas precedentes, habría que agregar La casa de cartón, de Martín Adán; 5 metros de poemas, de Carlos Oquendo de Amat; El nuevo absoluto, de Mariano Iberico; Kyra Kyralina (con prólogo de Romain Rolland) de Panait Istrati; Poesías de José María Eguren; La teoría del crecimiento de la miseria aliada aplicada a nuestra realidad, de Ricardo Martínez de la Torre; Panoramas, de Antenor Orrego; Tacna: Monografía histórico-geográfica, de Gerardo Vargas Hurtado; El mito de la revolución de agosto de 1930, de Víctor Rodrigo Alva; Cosa que debe saber un chauffer, de José Alves de Almeida; La constitución alemana de 1919 y Estudios de filosofía del derecho, de José León Barandiarán; Mis memorias de la guerra mundial 1914-1919, de Gustavo Otto; Legislación social: ley del empleado, doctrina crítica y legislación vigente, de Jorge Ramírez Otárola; El Amauta Atusparia. La sublevación indígena de Huaraz en 1885, de Ernesto Reyna Zegarra.

La lista es más amplia, pero lo mencionado nos da perfecta idea de que Mariátegui proyectó un conjunto de títulos y contenidos que constituyeran un cuerpo de ideas de vanguardia. A ello se debe sumar la audacia para lanzar al público un libro-objeto en forma de acordeón con los poemas de Oquendo de Amat. Por ello, tiene razón Diana Amaya cuando afirma que "...antes de Minerva no había rol de editor que acotara, que decidiera sobre la materialidad del libro como objeto. Se comenzó a hacer eso a partir de entonces. Tiene que ver ahí su proyecto de la revista Amauta, que consolida todo lo que había comenzado a vislumbrar" (Amaya).

El proyecto de los hermanos Mariátegui fue pensado como uno de largo plazo, se advierte su impacto e influencia en el campo cultural peruano en ciernes que la Sociedad contribuyó a configurar. 


\section{Contingencias de la edición en un contexto inestable}

Como en toda empresa editorial, la Sociedad Editora Amauta fue sensible a elementos del contexto intelectual y político, e incluso del aspecto personal de su líder. En efecto, el itinerario de la revista Amauta sufrió las consecuencias de la deteriorada salud de Mariátegui combinada con la coyuntura política. En junio de 1927 el gobierno de Augusto B. Leguía denunció un supuesto complot comunista que se tradujo en persecución de intelectuales y dirigentes políticos y obreros, entre ellos, el propio Mariátegui, quien fue recluido en el Hospital Militar de San Bartolomé. Esto implicó la suspensión de la continuidad de la publicación de Amauta, que desde el mes de mayo debió postergar su nueva entrega hasta diciembre.

En el número 17 de Amauta (setiembre de 1928) Mariátegui, por medio de su editorial "Aniversario y balance", oficializa su ruptura con Haya de la Torre y seguidores. Esta ruptura ideológica y política ocasionaría la fractura del campo intelectual en construcción. Los compañeros de un inicio quedarían al margen del proyecto editorial. Seoane, Spelucín, Orrego, De la Fuente y otros ya no acompañarían a José Carlos en su aventura empresarial-intelectual. Esto significaría un cambio en los márgenes de la amplitud para recibir colaboraciones: Mariátegui define a Amauta como una publicación socialista. Coincidentemente, también se produciría una modificación en su formato, en adelante se imprimiría en un tamaño más pequeño y contendría mayor número de páginas. Así le escribiría a Carlos Arbulú Miranda: "Este formato es más coleccionable y su armadura mucho más fácil..." (Lima, 29 de setiembre de 1928) (Mariátegui Tomo II 445).

Las decisiones se suceden en una vorágine. En octubre se constituye el Grupo de Lima que desembocaría en la creación del Partido Socialista y Mariátegui sería elegido su secretario general. Por nueva crisis en su salud debe sacar números dobles de Amauta. En noviembre funda el periódico Labor (a 10 ctvs., más barato que Amauta, que se vendía a 60 ctvs.): "Aspiramos a convertirlo en un periódico de 12 páginas, con 4 ilustraciones artísticas y nuevas secciones. Hay que comenzar modestamente, hasta que su economía y penetración estén aseguradas" (carta a Nicanor de la Fuente, Lima, 12 de noviembre de 1928) (471). Paralelamente, aparece su obra fundamental: 7 ensayos de interpretación de la realidad peruana, cuyo éxito en la consideración intelectual y en las propias ventas es innegable.

En 1929 Mariátegui se haría presente, mediante delegados, en distintas cumbres internacionales de trabajadores y de debate ideológico-político revolucionario y marxista; asimismo, constituye el Comité Organizador Pro-Central General de Trabajadores del Perú. Esta febril actividad político-organizativa derivó en que 
nuevamente el gobierno lo pusiera en la mira, esta vez acusándolo de ser parte de un complot judío. En setiembre su casa de Washington Izquierda sería allanada. Mientras tanto, busca ponerse al día con los números doble de Amauta; el periódico Labor sería clausurado. En el plano administrativo, Julio César confiere a José Carlos la gerencia de su Sociedad (Lima, octubre de 1929) (Archivo).

El final de Mariátegui se acercaba. En marzo de 1930 sería internado de emergencia en la Clínica Villarán; su salud se había deteriorado sin remedio: moriría el 16 de abril. Después de él, los tres números que salieron de Amauta tendrían otro carácter a los que José Carlos le había dado desde su fundación a la revista.

Si bien Amauta nació con un proyecto definido, las polémicas que Mariátegui sostuvo con Haya de la Torre y los apristas, así como en el interior del propio Grupo de Lima, y el constante deterioro de su salud y la hostilidad del gobierno lo obligaron a modificar y adecuar el carácter del proyecto, pero siempre con altos estándares de calidad en su forma y contenido. Mariátegui fue el punto de intersección y de unión de los tres ámbitos en los que se tuvo que desenvolver la revista Amauta y la propia Sociedad Editora Amauta: el de la empresa editorial, el del mundo intelectual-artístico y el del ideológico-político.

\section{Breves palabras finales}

La Sociedad Editorial Amauta, gracias a la capacidad y voluntad de José Carlos, y de la sagacidad empresarial de Julio César Mariátegui, expandió la cultura impresa en el Perú construyendo simultáneamente el contexto que le fuera favorable. Es decir, no actuó sobre un campo cultural constituido a plenitud, sino que, para tener éxito, la propia Sociedad debió conformar los elementos indispensables que le permitieran alcanzar sus objetivos. Así, la red de agencias, de los suscriptores, las vinculaciones nacional e internacional, y otros aspectos que hemos visto en las páginas precedentes, nos dicen de la importancia de la editora en una sociedad precariamente institucionalizada.

La sociabilidad intelectual que se constituyó bajo la sombra de la Sociedad Editora Amauta se caracterizó por los fuertes vínculos que estimuló entre autores, editores, libreros y lectores, que tuvieron como elemento de cohesión a las ideas, los debates, el pensamiento. La calidad intelectual de sus integrantes hizo que las fronteras entre el mundo de la materialización del objeto impreso y el mundo de las ideas y del conocimiento se compenetraran (y transgredieran) fácilmente. De ese modo, el autor podía ser editor, el traductor poeta, el gerente historiador del movimiento obrero, el publicista reseñista. Pero más allá aun: el autor-editor podía 
ser ideólogo, y al mismo tiempo organizador político, como lo fue el propio José Carlos Mariátegui. ${ }^{9}$

La base de todo lo descrito se encontraba definitivamente en el circuito de la palabra escrita, impresa o manuscrita. Sobre esta se erigió una incipiente pero muy encomiable República de las letras en el Perú. Como hemos ido demostrando, al objeto impreso se debe sumar la importancia vital que cobró la correspondencia. En efecto, para Mariátegui las cartas fueron fundamentales tanto para conformar una empresa editorial como para después fundar un partido político. Estaban en el ambiente ideas y planteamientos renovadores que buscaban alcanzar su materialidad; igualmente los sujetos que deseaban encarnarlos. Ahí radica la importancia de la Sociedad Editora Amauta de los hermanos José Carlos y Julio César Mariátegui: reconocer las exigencias interpretativas de su época y crear los espacios materiales de su concreción. Lamentablemente, la muerte del Amauta clausuró abruptamente un proyecto que sus sucesores no pudieron sostener en el tiempo.

9 Estudios de caso al respecto se pueden encontrar en Granados y Rivera Mir (2018). 


\section{Bibliografía}

Amaya, D. (2016). José Carlos Mariátegui, el editor. El Comercio. Lima, 10 de octubre.

Anónimo (2009). Historia de la imprenta y editorial Minerva. Boletín Casa Museo José Carlos Mariátegui. Lima: Instituto Nacional de Cultura, Setiembre.

Bello, K. (2019). Los traslapes entre el mundo intelectual y el mundo laboral: el Departamento técnico del FCE. Ponencia presentada en el Tercer Congreso Asociación Latinoamericana e Ibérica de Historia Socia (ALIHS). Lima: 3 de octubre.

Bourdieu, P. (2002) [1966]. Campo intelectual y proyecto creador. Campo intelectual y proyecto creador. Itinerario de un concepto. Buenos Aires: Editorial Montressor.

Coser, L. (1966). Hombres de ideas. El punto de vista de un sociólogo. México DF: Fondo de Cultura Económica.

Chartier, R. (1966). El orden de los libros. Barcelona: Gedisa.

Gonzales, O. (2014). La presencia judía en la izquierda peruana. Lima: Otra Mirada.

Granados, A. y Sebastián, M. (coordinadores) (2018). Prácticas editoriales y cultura impresa entre los intelectuales latinoamericanos en el sigloXX. México: El Colegio MexiquenseUAM Cuajimalpa.

Lomnitz, C. (2018). Nuestra América. Utopía y persistencia de una familia judía. México: Fondo de Cultura Económica.

Mariátegui, J. (1984). Correspondencia 1915-1930. Tomo I. Lima: Biblioteca Amauta,

Mariátegui, J. (1984). Correspondencia 1915-1930. Tomo II. Lima: Biblioteca Amauta.

Mariátegui, J. (2012). José Carlos Mariátegui. Formación, contexto e influencia de un pensamiento. Lima: Editorial Universitaria-Universidad Ricardo Palma.

McKenzie, D. (2015). Bibliografía y sociología de los textos. Madrid: Akal ediciones.

Melgar, R. (2009). Amauta: política cultural y redes artísticas e intelectuales. Simposio internacional Amauta, 80 años. Lima: Instituto Nacional de Cultura.

Podestá, G. (2018). Apología del aventurero José Carlos Mariátegui. Lima: Editorial Universitaria de la Universidad Ricardo Palma.

Rivera Mir, S. (2019). Trabajadores de imprenta, estudiantes de artes gráficas y militantes sindicales. Los difusos límites del mundo de la edición. Ponencia presentada en el Tercer Congreso Asociación Latinoamericana e Ibérica de Historia Social (ALIHS). Lima: 3 de octubre. 